Conclusions This is the first study to analyse putative associations between PBC and fluoride in drinking water across GB at small-area level. No statistically significant relationships were found.

\section{P1-97 DEMOGRAPHIC ANALYSIS OF OSTEOSARCOMA AND EWING SARCOMA FAMILY OF TUMOURS IN 0-49 YEAR OLDS IN GREAT BRITAIN, 1980-2005: A SMALL-AREA APPROACH}

doi:10.1136/jech.2011.142976c.90

\begin{abstract}
${ }^{1} \mathrm{~K}$ Blakey, ${ }^{*}{ }^{2} \mathrm{R}$ Feltobower, ${ }^{2} \mathrm{R}$ Parslow, ${ }^{1} \mathrm{P}$ James, ${ }^{1} \mathrm{~B}$ G Pozo, ${ }^{3} \mathrm{C}$ Stiller, ${ }^{3} \mathrm{~T}$ Vincent, ${ }^{4} \mathrm{P}$ Norman, ${ }^{2} \mathrm{P}$ McKinney, ${ }^{3} \mathrm{M}$ Murphy, ${ }^{5} \mathrm{~A}$ Craft, ${ }^{1} \mathrm{R}$ McNally. ${ }^{1}$ Institute of Health and Society, Newcastle University, Newcastle-upon-Tyne, UK; ${ }^{2}$ Paediatric Epidemiology Group, University of Leeds, Leeds, UK; ${ }^{3}$ Childhood Cancer Research Group, Department of Paediatrics, Oxford, UK; ${ }^{4}$ School of Geography, University of Leeds, Leeds, UK; ${ }^{5}$ Northern Institute of Cancer Research, Newcastle University, Newcastle-upon-Tyne, UK
\end{abstract}

Introduction Primary bone cancers (PBC) occur most often in young people. Osteosarcoma and Ewing sarcoma family of bone tumours (ESFT) are the most common sub-groups but aetiology remains unclear. Some childhood cancer rates are known to vary with socioeconomic status. Therefore, this study examined geographical patterning in osteosarcoma and ESFT incidence, diagnosed in 0-49 year olds in Great Britain (GB) during 1980-2005. The analysis focussed on putative associations with area characteristics including deprivation and population density (PD).

Methods Data were obtained from all regional cancer registries in GB. Negative binomial regression was used to examine the relationship between incidence rates with $\mathrm{PD}$ and Townsend deprivation score (TDS). These models were fitted to small-area census data aggregated by three age bands (0-14, 15-29 and 30-49 years) and gender with the logarithm of the 'at-risk' population as an offset.

Results There were 2566 osteosarcoma cases and 1650 ESFT cases. After adjustment for age and gender osteosarcoma incidence demonstrated a negative association with TDS (RR for one unit increase in deprivation level $=0.975$; $95 \%$ CI 0.963 to 0.986 ). ESFT incidence showed a negative association with PD (RR for increase of one person/ hectare $=0.981 ; 95 \%$ CI 0.972 to 0.989 ) and non-car ownership (RR for $1 \%$ increase of non-car ownership $=0.996$; $95 \%$ CI 0.993 to 1.000). Conclusion More deprived areas have lower osteosarcoma incidence. Higher ESFT incidence is associated with lower PD and higher car ownership levels. Both factors are rural area characteristics. Further study of environmental exposures or land use is recommended.

\section{P1-98 INEQUALITIES IN MEDICINES EXPENDITURE AMONG ADULTS: A POPULATION-BASED STUDY IN SOUTH OF BRAZIL}

doi:10.1136/jech.2011.142976c.91

${ }^{1} \mathrm{~A}$ Boing, ${ }^{*}{ }^{1} \mathrm{~K}$ Peres, ${ }^{2} \mathrm{~A}$ Bertoldi. ${ }^{1}$ Federal University of Santa Catarina, Florianópolis, Santa Catarina, Brazil, ${ }^{2}$ Federal University of Pelotas, Pelotas, Rio Grande do Sul, Brazil

Introduction Brazilian families' expenditure with health achieves high proportion of their incomes, especially to purchase medicines. The aim of this study was to investigate the associated factors with the proportion of income spent to purchase medicines in adults from 20 to 59 years of age.

Methods A cross sectional population-based study ( $n=1720$ ) was carried out in Florianópolis, Brazil, 2009. Commitment of $10 \%$ or more of family income (C10) with medicines expenditure (yes/no) was considered the outcome. Gender, age, skin colour, schooling, per capita family income, self-reported chronic diseases, hospitalisation in the last year, family health program coverage, and self-rated health were the exploratory variables. Crude and adjusted prevalence ratios (PR) were obtained through Poisson regression analyses. Results The prevalence of the C10 was $12.2 \%$ (95\% CI 10.4 to 13.9 ) and it was higher among women (PR 1.59, 95\% CI 1.16 to 2.18), people over 49 years of age (PR 1.95, 95\% CI 1.33 to 2.86), and those with a per capita family income lower than US\$242,90 (PR 2.38, $95 \%$ CI 1.42 to 4.02). Participants reporting chronic diseases (PR 2.17, 95\% CI 1.58 to 2.97), and those who were hospitalised in the last year (PR 1.47, 95\% CI 1.02 to 2.12) was more likely to present C10. Conclusions The results suggest remarkable social inequalities in medical expenses in a Brazilian adult population. Social and economic policies to reduce such vulnerability are necessary.

\section{P1-99 A POLICY EFFECTIVENESS-FEASIBILITY LOOP FOR EVIDENCE-BASED PUBLIC HEALTH POLICY}

doi:10.1136/jech.2011.142976c.92

${ }^{1} \mathrm{~S}$ Bowman, ${ }^{*}{ }^{2} \mathrm{~N}$ Unwin, ${ }^{3} \mathrm{~J}$ Critchley, ${ }^{4} \mathrm{~A}$ Husseini, ${ }^{5} \mathrm{~B}$ Unal, ${ }^{6} \mathrm{~F}$ Fouad, ${ }^{6} \mathrm{~W}$ Maziak, ${ }^{7} \mathrm{H}$ B Romdhane, ${ }^{8} \mathrm{~S}$ Capewell. ${ }^{1}$ Institute of Health and Society, University of Newcastle, Newcastle Upon Tyne, UK; ${ }^{2}$ The Faculty of Medical Sciences, University of the West Indies, Bridgetown, Barbados; ${ }^{3}$ St. George's Hospital Medical School, University of London, London, UK; ${ }^{4}$ Institute of Community and Public Health, Birzeit University, Birzeit, Occupied Palestinian Territory; ${ }^{5}$ Department of Public Health, School of Medicine, Dokuz Eylul University, Izmir, Turkey; ${ }^{6}$ Syrian Center for Tobacco Studies, Aleppo, Syria; ${ }^{7}$ National Public Health Institute, CVD Epidemiology and Prevention Research Laboratory, Tunis, Tunisia; ${ }^{8}$ School of Population Community and Behavioural Sciences, University of Liverpool, Liverpool, UK

Introduction While public health policy could profoundly effect health status ${ }^{1}$, research informing policy-making and implementation is underutilised. ${ }^{1-5}$ A range of evidence types are required to support policy-making, and involving policy makers in generating and evaluating evidence is important. This work aims to develop, implement and evaluate an interactive approach to informing policy for preventing and managing cardiovascular disease (CVD) and diabetes (focusing on four territories with a high disease burden: Palestine, Turkey, Tunisia and Syria).

Methods and Results Three main types of research activity are proposed: 1. Epidemiological modelling: three models estimate major risk factor trends including relative contribution to overall reduction in $\mathrm{CHD}$ deaths.

2. Situation analysis: three main elements are investigated using mixed methods. Analysis will suggest acceptable and feasible interventions and opportunities and barriers for implementation.

3. Economic modelling: potentially effective and feasible options will be evaluated, including country-specific cost and cost-effectiveness ratios.

A 'policy effectiveness-feasibility loop' model (based on an 'equity effectiveness loop'7) is proposed to link evidence types and facilitate its systematic, operational use in policy-formulation. Illustrative findings from using this model in four focus countries will be described. Policy makers are involved throughout, informing the situation analysis and choosing and appraising options for implementation.

Conclusion Other non-linear models exist for how research influences policy-making ${ }^{6}$. This work proposes a pragmatic framework to: combine all evidence types (particularly cost effectiveness); involve policy makers; and use evidence to develop policy options (initially for CVD and diabetes prevention). Next steps for evaluation are suggested.

\section{REFERENCES: AVAILABLE ON REQUEST.}

\section{P1-100 I2SARE (INDICATEURS DE SANTÉ DANS LES REGIONS D'EUROPE) EUROPEAN REGIONAL HEALTH PROFILES}

doi:10.1136/jech.2011.142976c.93

T Braun,* G Bryant, C Bradford, J Wilkinson. NEPHO (North East Public Health Observatory), Stockton, UK

Introduction The I2SARE project has developed health profiles for 263 regions in 26 European member states. Information at regional 
level demonstrates the distinctiveness of regions within countries. The project aims to support the development of health policy and systems at regional, national and European level through comparable health and health service information.

Methods The I2SARE project evolved from the ISARE I-III projects which explored regional boundaries and comparable indicators. In 2008 information for the 37 indicators was collected by project partners in each country. Datasets were subsequently cross validated, indicators calculated and entered into the regional health profiles. Each indicator compares the region with the lowest and highest values for the country and Europe and the European median. Results The European regional health profiles present information on "demography and socioeconomic conditions", "mortality", "morbidity", "risk factors" and "health professionals and healthcare services". The profiles showed that the English regions and devolved countries have a very high proportion $(18 \%-29 \%)$ of obese adults compared to a median of $14 \%$ in Europe. In France perinatal mortality was particularly high while female premature mortality for circulatory diseases was among the lowest in Europe.

Conclusion The European regional health profiles for the first time provide internationally comparable health and health service information on regional level. The information can be used to support regional and national governments and health systems to improve the health of their population and to address inequalities.

\section{REFERENCE}

http://www.i2sare.eu.

\section{P1-101 CONTRASTS BETWEEN RECIPIENTS OF FORMAL CARE AND THOSE WITHOUT: ENGLISH LONGITUDIINAL STUDY OF AGEING 2008-2009}

doi:10.1136/jech.2011.142976c.94

E Breeze.* UCL, London, UK

Introduction England has a market-led welfare state with meanstested services. Funding of care is a live issue. Objectives were to compare socio-demographic characteristics and functioning according to sources of help received for disabilities.

Methods Cross-sectional analysis of participants in the fourth round of fieldwork from the English Longitudinal Study of Ageing. Subjects analysed $(n=5653)$ were aged 50 and over, living in the community and reported difficulty with at least one motor skill, activity of daily living, or instrumental activity of daily living.

Results Among the eligible participants 58\% received no help $(\mathrm{NH})$, $34 \%$ only informal help (IH), $4 \%$ paid help but no state help (PH), and $4 \%$ state help with or without other sources $(\mathrm{SH})$. The $\mathrm{PH}$ and $\mathrm{SH}$ groups were older than the other two and less likely to have a partner but the wealthiest were over-represented in the $\mathrm{PH}$ group whereas the SH group were most likely to be in the poorest wealth quintile. The SH group scored worst on subjective and objective measures of physical and cognitive functioning whereas the $\mathrm{PH}$ group were similar to the IH group. The $\mathrm{SH}$ group were most likely to have a mobility aid or an adaptation in their home. The NH group mainly had difficulties with motor skills and performed better cognitively.

Conclusion In the English system small group with substantial problems in functioning receives state help. Another small group pays privately for help, possibly substituting informal help. The sources of help appear to reflect some indicator of need.

\section{P1-102 PREVALENCE OF DENTAL INJURIES AND ITS ASSOCIATION WITH ALCOHOL USE AMONG ADOLESCENTS}

doi:10.1136/jech.2011.142976c.95

${ }^{1} \mathrm{~V}$ S C Brizon, ${ }^{2} \mathrm{P}$ M 0 Filho, ${ }^{1} \mathrm{E} F$ Ferreira, ${ }^{1} \mathrm{R}$ A Ferreira, ${ }^{1,2} \mathrm{P}$ M Zarzar.

${ }^{1}$ Universidade Federal de Minas Gerais, Belo Horizonte, Minas Gerais, Brazil;
${ }^{2}$ Universidade Federal dos Vales do Jequitinhonha e Mucuri, Diamantina, Minas Gerais, Brazil

Introduction Alcohol consumption is a substantial and growing health problem among adolescents. However, it is not known whether the dental injury is associated with alcohol consumption. Methods In 2009-2010 we carried out a cross-sectional study among a random sample of 687 adolescents (aged 14-19 years) from public and private schools in Diamantina, Minas Gerais, Brazil. Information on dental injuries and alcohol consumption were collected via a clinical examination by one researcher (intra-examiner $\kappa=0.93$ ) and a self-administered questionnaire: Alcohol Use Disorders Identification Test (AUDIT), validated in Brazil. Study in public or private school was used for socioeconomic indicator.

Results The prevalence of dental injuries was $26.6 \%$ and the prevalence of risk from hazardous levels of alcohol consumption was $44 \%$. The traumatic dental injuries were significantly associated with the high risk of alcohol consumption $(p=0.031)$, hazardous use $(p=0.009)$ and binge drinking $(p=0.036)$. The Results of the logistic regression revealed that hazardous use (OR $-1.4 \mathrm{CI} 1.007$ to 2.061), remained associated with traumatic dental injury independent of other variables as age, gender, overjet and type of school.

Conclusions There is a high prevalence of traumatic dental injuries and hazardous alcohol use among adolescents, and alcohol consumption was associated with the prevalence of dental injuries.

\section{P1-103 BIAS OF IMPEDANCE EQUATION FOR ESTIMATING EXTREMES OF BODY COMPOSITION}

doi:10.1136/jech.2011.142976c.96

B Bronhara, ${ }^{*}$ V Baltar. University of Sao Paulo, Sao Paulo, Brazil

Introduction Resistance and reactance are often used in body composition compartment regressions which require the assumptions that the body is a cylinder of constant transversal area and the hydration is constant. Problems can be found in extremes of body composition, when those assumptions are not met.

Objective To analyse if the impedance equation estimative of body fat (BF) agrees with that provided by the Dexa reference method.

Methods We used representative data of the North American population, entitled Nhanes 2003-3004. Individuals aged 20-49 from both sexes $(n=1716)$ were selected and information on $B F \%$ estimated by Dexa, resistance, reactance, height and weight were used. Impedance equation was proposed by Kyle et al for lean body mass: -4.104 $+\left(0.518 *\right.$ Height $^{2} /$ Resistance $)+(0.231 *$ weight $)+(0.130 *$ Reactance $)$ $+(4.229 \times$ sex $) ;$ Sex: $\operatorname{man}=1$ and woman $=0$. Weight minus lean mass provided the $\mathrm{BF} \%$. BF\% was divided in four categories: $15 \%, 15 \%-$ $25 \%, 25 \%-35 \%$, and $35 \%-45 \%$. $\kappa$ Statistic was used for evaluating agreement between both methods, in each category of $\mathrm{BF} \%$, in each sex Results $\kappa$ Statistics from lowest to highest categories of $\mathrm{BF} \%$ were $0.35 ; 0.38 ; 0.47 ; 0.46$ and $0.39 ; 0.51 ; 0.48$ and 0.63 for male and female, respectively (all $\mathrm{p}<0.001$ ).

Conclusion Estimates of \%BF by impedance equation and Dexa differ, mainly in lowest categories of \%BF and among males, but not for highest category among females. Caution must be taken in using such equations among individuals with extreme body composition compartments.

\section{P1-104 COMMUNITY SYNDROMIC SURVEILLANCE SYSTEM USING INFORMATION AND COMMUNICATION TECHNOLOGY IN PARAGUAY}

doi:10.1136/jech.2011.142976c.97

${ }^{1,2} \mathrm{~A}$ Cabello, ${ }^{*} \mathrm{P}$ Galván, ${ }^{1} \mathrm{~V}$ Cane, ${ }^{3} \mathrm{X}$ Basogain, ${ }^{1} \mathrm{M}$ Cabral, ${ }^{1,2} \mathrm{M}$ Samudio, ${ }^{1,2} \mathrm{M}$ Paez, ${ }^{1} \mathrm{M}$ Ascurra, ${ }^{2}$ I Allende. ${ }^{1}$ Instituto de Investigaciones en Ciencias de la Salud, UNA, Asuncion, Paraguay; ${ }^{2}$ Dirección General de Vigilancia de la Salud, MSPBS, Asuncion, Paraguay; ${ }^{3}$ Universidad del país Vasco, UPV, Bilbao, Spain 